\title{
RECURRENT MEDIAL SWIVEL DISLOCATION OF THE FOOT
}

\section{J. A. N. VERHAAR}

Injuries involving the midtarsal joint are rare. A medial stress injury may lead to a medial subtalar dislocation or to a variant of it, termed the medial swivel dislocation (Main and Jowett 1975). In this the navicular is displaced medially on the talus, but the calcaneocuboid joint stays intact and the subtalar joint is not dislocated. The
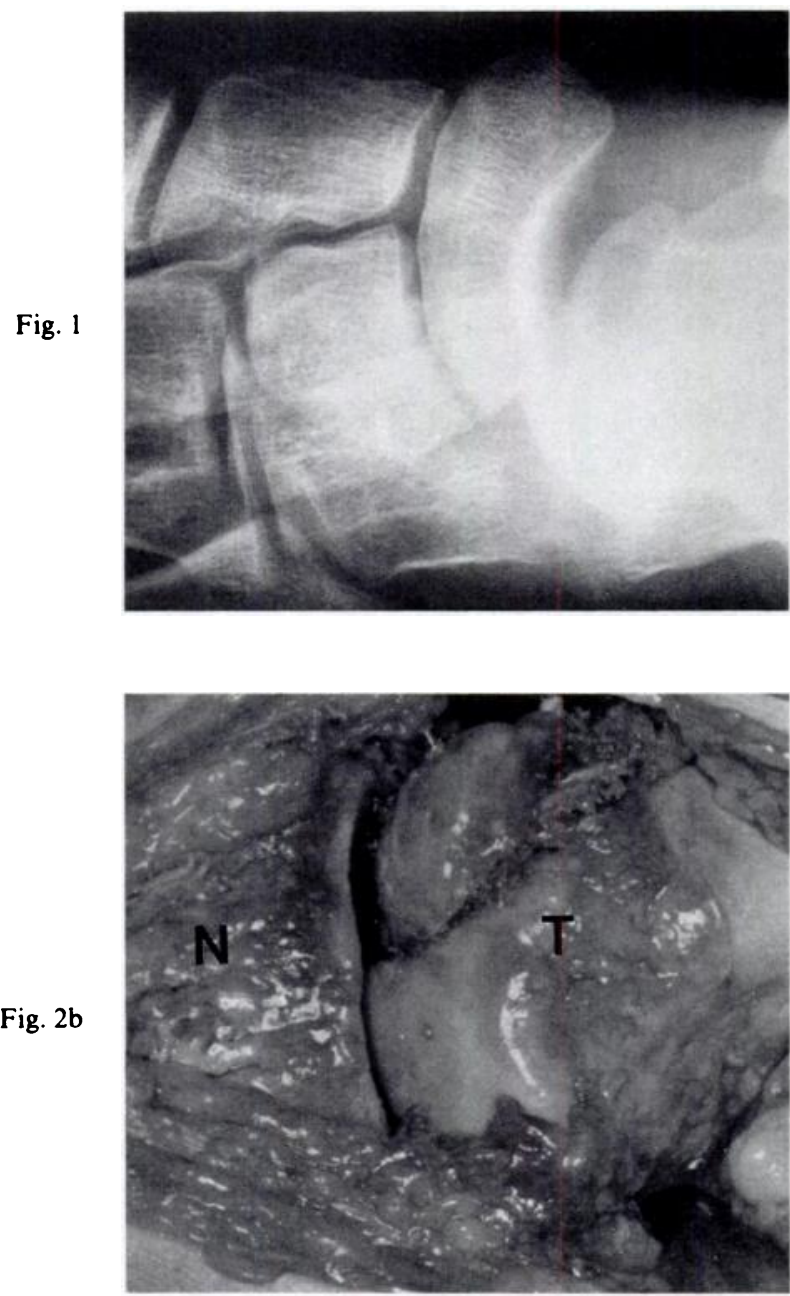

calcaneus rotates on the intact interosseous talocalcaneal ligament. Main and Jowett described seven cases of medial swivel dislocation, all seen shortly after the injury. We report a recurrent swivel dislocation, seen three months after injury.

J. A. N. Verhaar, MD, Consultant Orthopaedic Surgeon Department of Orthopaedic Surgery, University Hospital, PO Box 1918, 6201 BX Maastricht, The Netherlands.

(C) 1990 British Editorial Society of Bone and Joint Surgery $0301-620 X / 90 / 1$ R $42 \$ 2.00$

J Bone Joint Surg [Br] 1990; 72-B : 154-5.
Case report. A 16-year-old boy gave a three-month history of painful giving-way in the left ankle after a fall from his motorcycle. He could provoke an audible click in the ankle region by plantarflexion and inversion of the forefoot and the forefoot remained in a supinated position after the click. Plantarflexion $\left(60^{\circ}\right)$, dorsiflexion $\left(15^{\circ}\right)$ and

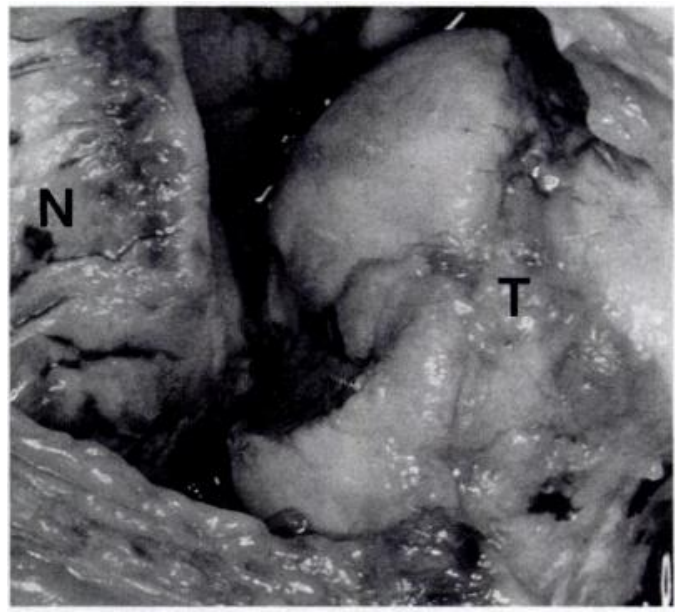

Fig. 2a

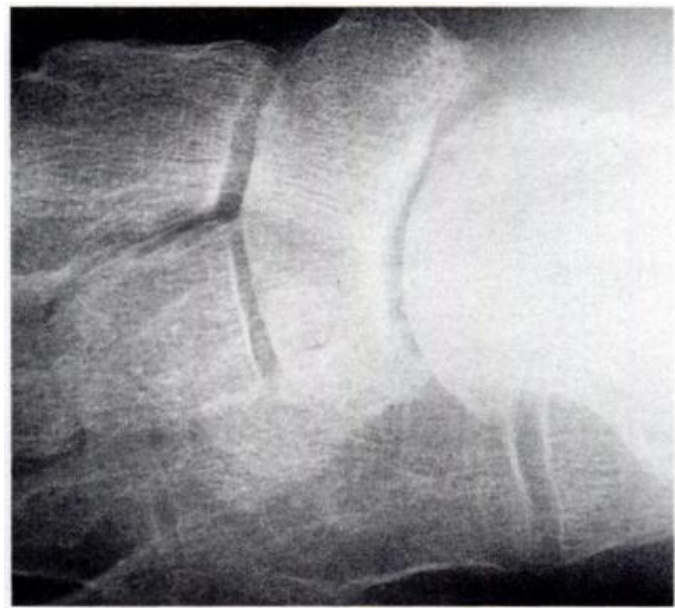

Fig. 3

eversion were normal, but inversion was a little painful, especially over the talonavicular joint. Forced plantarflexion and inversion resulted in a subluxation of this joint. Radiographs showed an old impaction fracture of the medial margin of the talus. When the talonavicular joint was subluxed, the calcaneocuboid joint remained intact (Fig. 1). Recurrent medial swivel dislocation was diagnosed. Treatment in plaster failed and months after the accident he was operated upon.

A medial dorsal incision over the talonavicular joint was used. Figure 2a shows that the talar head (T) was biconcave after the fracture and that the medial part of 
the head was displaced dorsomedially from the navicular (N). Because the patient was young, we opted for reconstruction rather than arthrodesis. Using the oscillating saw, the dislocated medial part of the talar head was freed and used as a free transplant to the original site (Fig. 2b). K-wires were used for fixation. Additionally, bone grafting was performed from the proximal tibia. A below-knee plaster was worn for eight weeks.

Two years later the patient had a painless foot and no subluxation. He walked normally and had no restriction of his activities. Plantarflexion was limited by $20^{\circ}$ and inversion was moderately limited. Radiographically the joint looked almost normal. The radiographs showed normal bone structure of the talar head (Fig. 3).

Discussion. For acute cases of medial swivel foot, Main and Jowett (1975) advised treatment by prompt reduction and immobilisation. They saw no justification for early arthrodesis, but they advocated triple arthrodesis in case of persistent symptoms.

The long-term results of a reconstruction as we performed it are difficult to predict. However, the shortterm results are good and compare favourably with those of arthrodesis. Moreover, this option is still open should the initial good result wane.

In conclusion, it may be said that reconstruction of the talar head after a neglected impaction fracture and medial swivel foot may be a good alternative to arthrodesis.

No benefits in any form have been received or will be received from a commercial party related directly or indirectly to the subject of this article.

\section{REFERENCE}

Main BJ, Jowett RL. Injuries of midtarsal joint. J Bone Joint Surg [ Br] $1975 ; 57-B: 89-97$.

\section{TRANSEPIPHYSEAL FEMORAL NECK FRACTURE AT BIRTH}

\section{MARGARET J. FAIRHURST, I. MCDONALD}

We report a seven year follow-up on a child who sustained a displaced femoral neck fracture during delivery.

Case report. The child, now aged seven, was born to a diabetic mother after an extremely difficult delivery at 38 weeks; this involved internal version and breech extraction. In addition to the hip injury the baby had some cerebral irritation, a fractured clavicle and an Erb's palsy.

An orthopaedic consultation was sought at seven days when generalised swelling and bruising had mostly subsided, but the left thigh remained swollen, the leg was externally rotated and any movement of the leg precipitated crying. Plain radiographs (Figs la, b) suggested a dislocation of the left hip but epiphyseal separation could not be excluded.

At 10 days of age the infant was anaesthetised. It was then found that a hard swelling in the femoral triangle moved with the femur. It was thought to be the femoral head but arthrography (Fig. 2) showed that the head was in the socket; there was, however, a transepiphyseal fracture. The arthrogram of the unaffected right hip was normal.

The left hip was opened via an anterior approach; there was a severely displaced fracture between the cartilaginous head and neck and the bony metaphysis of

M. J. Fairhurst, FRCS (Glas), Orthopaedic Registrar

I. McDonald, FRCS (Glas), FRACS (Orth), Consultant Orthopaedic Surgeon

Rotorua Hospital, Private Bag, Rotorua, New Zealand.

Correspondence to Ms M. J. Fairhurst.

(C) 1990 British Editorial Society of Bone and Joint Surgery 0301-620X/90/1R43\$2.00

J Bone Joint Surg [Br] 1990; 72-B : 155-6.

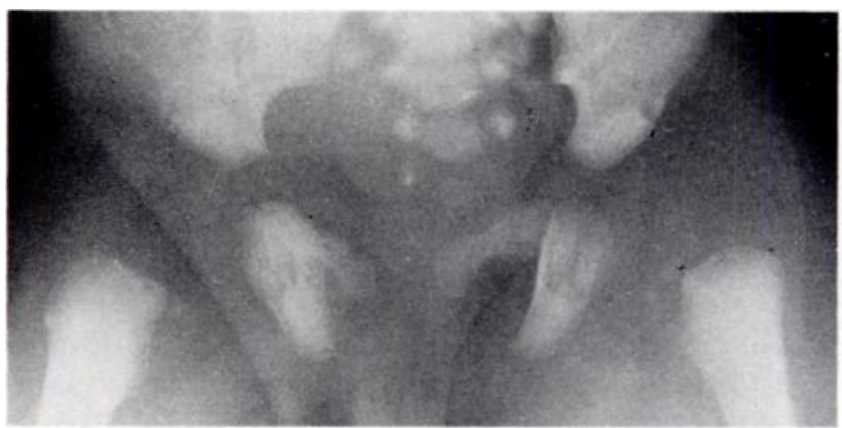

Fig. 1a

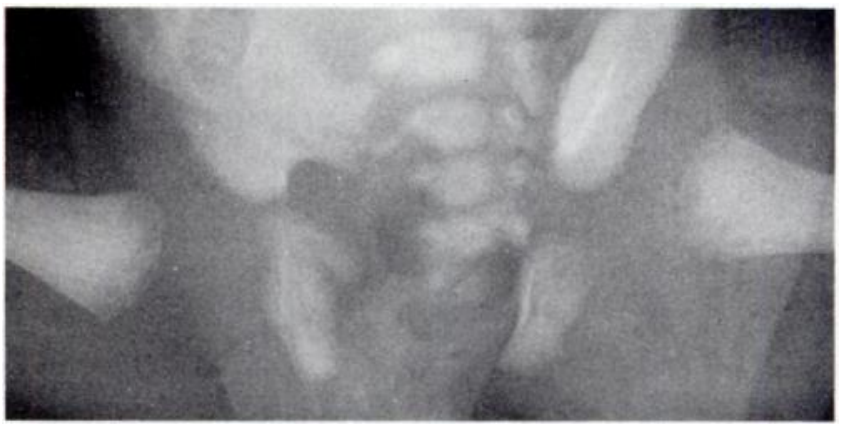

Fig. 1b

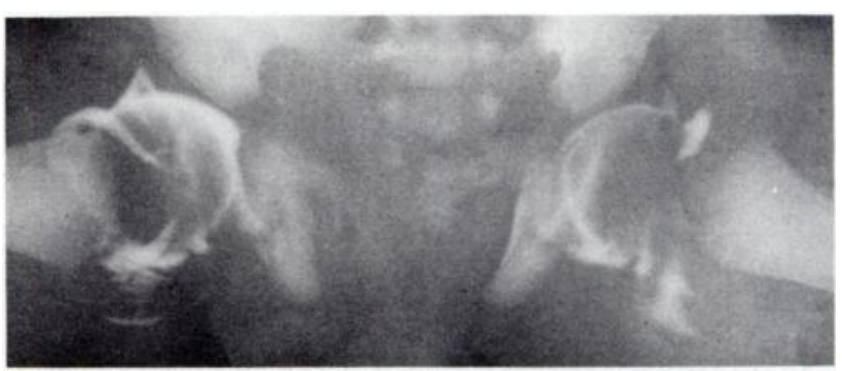

Fig. 2 